\title{
Effects of ischemic phrenic nerve root ganglion injury on respiratory disturbances in subarachnoid hemorrhage: an experimental study
}

Hızır Ulvi'1, Recep Demir ${ }^{1}$, Recep Aygül', Dilcan Kotan'1 ${ }^{1}$ Muhammet Çalik², Mehmet Dumlu Aydin ${ }^{3}$

1Department of Neurology, Faculty of Medicine, Atatürk University, Erzurum, Turkey 2Department of Pathology, Faculty of Medicine, Atatürk University, Erzurum, Turkey 3Department of Neurosurgery, Faculty of Medicine, Atatürk University, Erzurum, Turkey

Submitted: 7 June 2011

Accepted: 19 November 2011

Arch Med Sci 2013; 9, 6: 1125-1131

DOI: 10.5114/aoms.2013.39227

Copyright $\odot 2013$ Termedia \& Banach

\section{Abstract}

Introduction: Phrenic nerves have important roles on the management of respiration rhythm. Diaphragm paralysis is possible in phrenic nerve roots ischemia in subarachnoid hemorrhage (SAH). We examined whether there is a relationship between phrenic nerve root ischemia and respiratory disturbances in $\mathrm{SAH}$. Material and methods: This study was conducted on 5 healthy control and 14 rabbits with experimentally induced SAH by injecting autologous blood into their cisterna magna. Animals were followed up via monitors for detecting the heart and respiration rhythms for 20 days and then decapitaed by humanely. Normal and degenerated neuron densities of phrenic nerve root at the level of C4 dorsal root ganglia (C4DRG) were estimated by Stereological methods. Between the mean numerical density of degenerated neurons of C4DRG and respiratory rate/minute of groups were compared statistically.

Results: Phrenic nerve roots, artery and diaphragm muscles degeneration was detected in respiratory arrest developed animals. The mean neuronal density of C4DRG was $13272 \pm 1201 / \mathrm{mm} 3$ with a mean respiration rate of $23 \pm 4 / \mathrm{min}$ in the control group. The mean degenerated neuron density was $2.240 \pm 450 / \mathrm{mm}^{3}$ and respiration rhythm was $31 \pm 6 / \mathrm{min}$ in survivors. But, the mean degenerated neuron density was $5850 \pm 650 / \mathrm{mm}^{3}$ and mean respiration rhythm was 34 $\pm 7 / \mathrm{min}$ in respiratory arrest developed animals $(n=7)$. A linear relationship was noticed between the degenerated neuron density of C4DRG and respiraton rate $(r=-0.758 ; p<0.001)$.

Conclusions: Phrenic nerve root ischemia may be an important factor in respiration rhythms deteriorations in SAH which has not been mentioned in the literature.

Key words: C4 dorsal root ganglia, phrenic nerve, respiration, subarachnoid hemorrhage.

\section{Introduction}

The management of patients with subarachnoid hemorrhage (SAH) should achieve two major goals: (1) prevention of subsequent bleeding and (2) prevention and treatment of cerebral vasospasm, which usually develops between 4 and 14 days after SAH [1]. Cerebral vasospasm is a common, formidable, and potentially devastating complication in patients who have sustained $\mathrm{SAH}$.

\author{
Corresponding author: \\ Mehmet D. Aydin \\ Department of Neurosurgery \\ Faculty of Medicine \\ Atatürk University \\ 25240, Erzurum, Turkey \\ E-mail: nmda11@hotmail.com \\ Hızır Ulvi \\ Department of Neurology \\ Faculty of Medicine \\ Atatürk University, \\ 25240 Erzurum, Turkey \\ Phone: 0904423422531 \\ E-mail: hizirulvi@yahoo.com
}


Cisternal injection of autologous blood produces spasm of basilar and anterior spinal arteries. This model has been used successfully in cats and dogs in an effort to understand the mechanism involved in the development and maintenance of cerebral vasospasm after $\mathrm{SAH}[1-5]$. Although known for more than five decades, cerebral vasospasm is one of the most challenging complications following SAH. Cerebral vasospasm after SAH has been the subject of substantial research interest, but the underlying pathogenic mechanisms remain obscure. This seriously aggravates the vital prognosis, with a 1.5- to 3fold increase in mortality in the first 2 weeks after $\mathrm{SAH}$. In survivors, it is the major cause of disability, with a $25 \%$ decrease in excellent outcome [6-9]. Increasing SAH volumes were associated with greater abnormalities in the respiratory pattern, consisting of apnea and hyperventilation. These larger volumes were also associated with hypoxemia [10]. In another study, the authors showed that respiratory failure is related to neurological outcome following $\mathrm{SAH}$, although it is not commonly the primary cause of death from medical complications [11].

Vasospasm after SAH may cause ischemic neurodegeneration in DRG of the phrenic nerve and can lead to abnormalities in the respiratory pattern. Therefore, we examined whether there is a relationship between the neuron density of phrenic nerve $C_{4}$ dorsal root ganglia $\left(C_{4 D R G}\right)$ segments and deterioration of respiration rhythms in $\mathrm{SAH}$.

\section{Material and methods}

This study was performed in 19 anesthetized adult male New Zealand rabbits ( $3.7 \pm 0.4 \mathrm{~kg}$ ). Experiments were carried out according to the guidelines set by the ethical committee of Atatürk University. Five of the animals were used as a control group. The remaining 14 were left hungry for $6 \mathrm{~h}$ before surgical intervention. A balanced injectable anes-

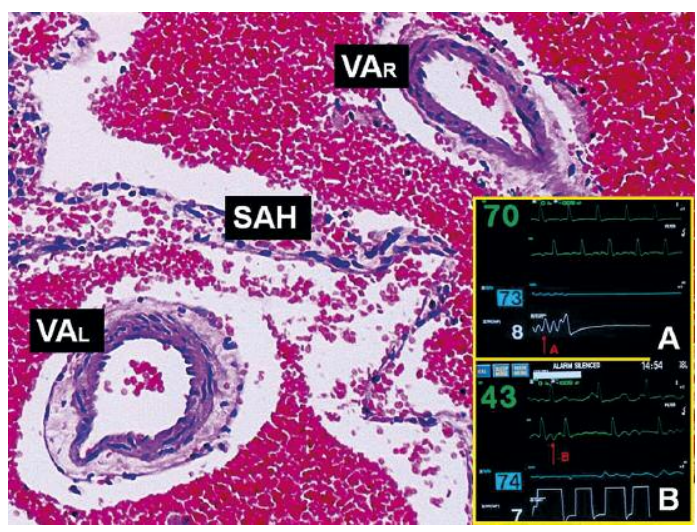

Figure 1. Spinal subarachnoid hemorrhage (SAH); right (VAR) and left (VAL) vertebral arteries are seen in the background picture ( $L M, H+E, 40 \times)$. At the right bottom corner, monitorization data are shown. Respiration (A) and heart rhythm disturbances (B) are seen on the monitor thesia was used for reducing pain and mortality. Before the operation, 3D computed tomography was performed on the same animals and their cranial base anatomy was evaluated. After inducing anesthesia with isoflurane by a face mask, $0.2 \mathrm{ml}$ $\mathrm{kg}$ of the anesthetic combination (ketamine $\mathrm{HCL}$ $150 \mathrm{mg} / 1.5 \mathrm{ml}$; xylazine HCL 30 mg/1.5 ml; and distilled water $1 \mathrm{ml}$ ) was subcutaneously injected before surgery. Then, the posterior craniocervical regions were saved and sterilized with iodine solutions. During the operation, the cranium was positioned hyper anteflexion and $0.5 \mathrm{ml}$ of autologous blood was taken from the auricular artery and injected into the cisterna magna via a 22-gauge needle in about one minute.

Heart and respiratory rhythms were followed up and detected via monitors for 20 days without any medical treatment and then all animals were sacrificed. Diaphragm paralysis was defined via a monitor and clinical observations. Recurrent bleeding foci were detected in the animals with respiratory disturbances or dead ones (Figure 1). All $C_{4 D R G}$ and $C_{4}$ roots together with their ganglions were removed bilaterally for histological examination. They were kept in 10\% formalin solution for 7 days; then, 1- $\mu \mathrm{m}$ tissue sections were taken and stained with hematoxylin and eosin. Cellular angulations, nuclear shrinkage, cytoplasmic condensations, and height loss were the accepted injury criteria for phrenic nerve root ganglions ( $\left.\mathrm{NC}_{4 \mathrm{DRG}}\right)$. Stereological methods should be used to estimate cell density in all studies of histological specimens [12-14]. For the estimation of neuron density of $C_{4 D R G}, C 4$ roots together with their ganglions were extracted bilaterally. Then, they were embedded in paraffin blocks in a horizontal position to observe all roots during the histopathological examination. The physical dissector method was used to evaluate the numbers of neurons of $C_{4 D R G}$. This method can easily estimate the particle number, be readily performed, is intuitively simple, is free from assumptions about particle shape, size and orientation, and is not affected by overprotection and truncation. Two consecutive sections (dissector pairs) obtained from tissue samples with a named reference were mounted on each slide. Reference and look-up sections were reversed in order to double the number of dissector pairs without taking new sections. The mean numerical density of neurons of $\mathrm{NC}_{4 \mathrm{DRG}}$ per $\mathrm{mm}^{3}$ was estimated using the following formula: the mean numerical density of normal neurons (NN) and degenerated neurons (DN) in the $C_{4 D R G}$ $\left(\mathrm{NN}_{\mathrm{n} \text { (number) }} / \mathrm{DNn}\right.$ ) per cubic millimeter was estimated using the following formula [12-14]: $\mathrm{NN}_{\mathrm{n}} / \mathrm{DN}_{\mathrm{n}}=\Sigma \mathrm{Q}^{-} / \Sigma \mathrm{A} \times d$, where: $\Sigma \mathrm{Q}-\mathrm{N}$ is the total number of counted neurons appearing only in the reference sections, $d$ is the section thickness, and $A$ is the area of the counting frame. The most effec- 

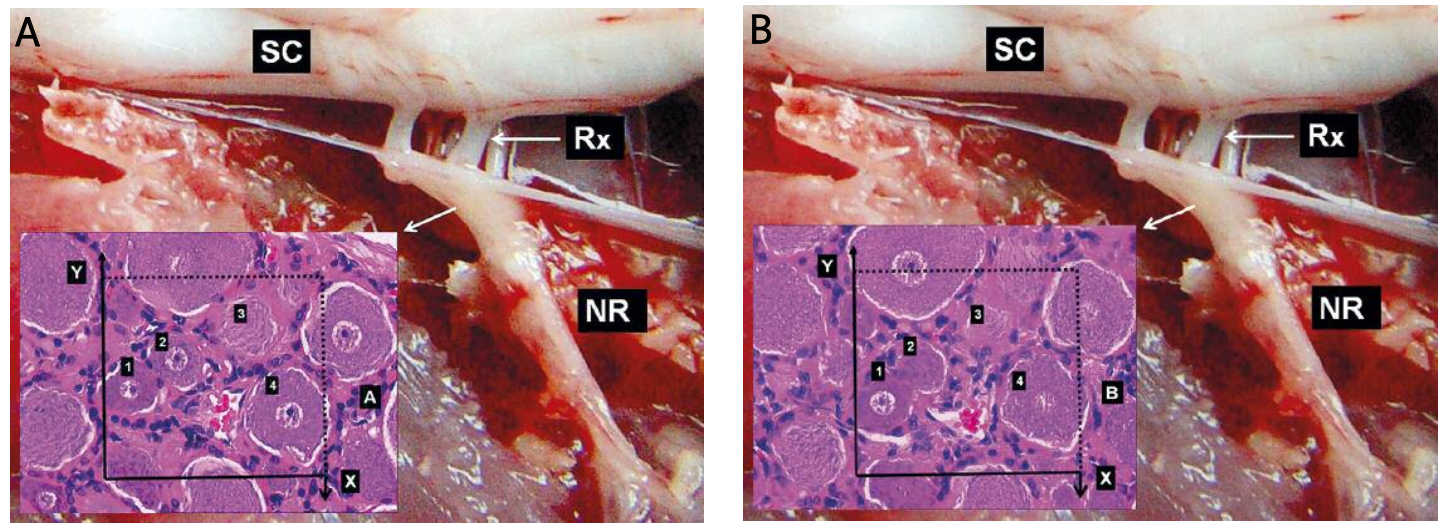

Figure 2. Stereological histopathological demonstration of the phrenic nerve at $\mathrm{C}_{4}$ level dorsal root ganglia $\left(\mathrm{C}_{4 \mathrm{DRG}}\right)$. Stereological cell counting method of $\mathrm{C}_{4 D R G}$ is seen in a rabbit. Application of the physical dissector method in which micrographs in the same fields of view $(A B)$ are taken from two parallel adjacent thin sections separated by a distance of $5 \mu \mathrm{m}$. Upper and right lines of unbiased counting frames represent the inclusion lines and the lower and left lines including the extensions are exclusion lines. Any neuron nucleolus hitting the inclusion lines is excluded and nucleolus profiles hitting the inclusion lines and located inside the frame are counted as dissector particles unless their profile extends up to the look-up section. The number of neurons from the two dissectors occurs in a volume given by the product of the counting frame area and distance between the sections. The mean numerical density of neurons of phrenic nerve root ganglions ( $\mathrm{NC}_{4 \mathrm{DRG}}$ ) per $\mathrm{mm}^{3}$ was estimated using the following formula: $\mathrm{NC}_{4 \mathrm{DRG}}=\Sigma \mathrm{Q}-\mathrm{N} / \mathrm{txA}$, where $\Sigma Q-N$ is the total number of counted neurons appearing only in the reference sections, $t$ is the section thickness, $A$ and $B$ are the area of the counting frame (Figures $1 \mathrm{~A}$ and $\mathbf{B}$ ). In this application, the nucleoli of normal neurons marked with ' 3,4 ' are dissector particles on section A as it disappeared in section B. Gross anatomical representation of C4DRG is seen in the background of the pictures

$N R$ - nerve root, SC - spinal cord, $R x$ - radix

tive way of estimating $\Sigma A$ for the set of dissectors is using $\Sigma A=\Sigma P a$, where $\Sigma P$ is the total number of counting set frame points and $\mathrm{a}$ is a constant area associated with the set point (Figures $2 \mathrm{~A}$ and $\mathrm{B}$ ). The Cavalieri volume estimation method was used to obtain the total number of neurons in each specimen [12-14]. The total number of neurons was calculated by multiplication of the volume $\left(\mathrm{mm}^{3}\right)$ and numerical density of neurons in each phrenic nerve $C_{4 D R G}$. The number of normal and degenerated neurons of $C_{4 D R G}$ of all animals was counted.

\section{Statistical analysis}

Mean density of remaining normal neurons and respiratory rate/min between the groups were compared statistically. We also checked for a correlation between neuron density and respiratory rate. Analysis of variance (ANOVA) and Pearson correlation were used during statistical analysis.

\section{Results}

The mean neuronal density of $\mathrm{C}_{4 \mathrm{DRG}}$ in the control group was $13272 \pm 1201 / \mathrm{mm}^{3}$ in normal survivors with a mean respiration rate of $23 \pm 4 / \mathrm{min}$ (Figure 3); the mean normal neuron density of $C_{4 D R G}$ was estimated as $11.412 \pm 670 / \mathrm{mm}^{3}$ in survivors with respiratory disturbance, the mean degenerated neuron density was estimated as 2.240 $\pm 450 / \mathrm{mm}^{3}$ and mean respiration rhythm was 31 $\pm 6 / \mathrm{min}$; the mean normal neuron density of $C_{4 D R G}$ was estimated as $7230 \pm 967 / \mathrm{mm}^{3}$ in animals with respiratory arrest, the mean degenerated neuron density was $5850 \pm 650 / \mathrm{mm}^{3}$, and mean respiration rhythm was detected as $34 \pm 7 /$ min before arrest (Figure 4). Results are summarized in Table I. There was a significant difference in the mean neuron density of $C_{4 D R G}$ between all groups $(p<0.01)$. Respiratory rate before death was significantly different between the control group and the respiratory arrest group ( $p=0.04$ ). Paralyzed diaphragm was seen in respiratory arrest developed animals after $\mathrm{SAH}$ (Figure 5). A linear relationship was noted between the neuronal density in the $C_{4 D R G}$ and respiratory rate $(r=-0.758 ; p<0.001)$ (Figure 6).

\section{Discussion}

Cerebral arteries, which are innervated by several systems, contribute to the autonomic control

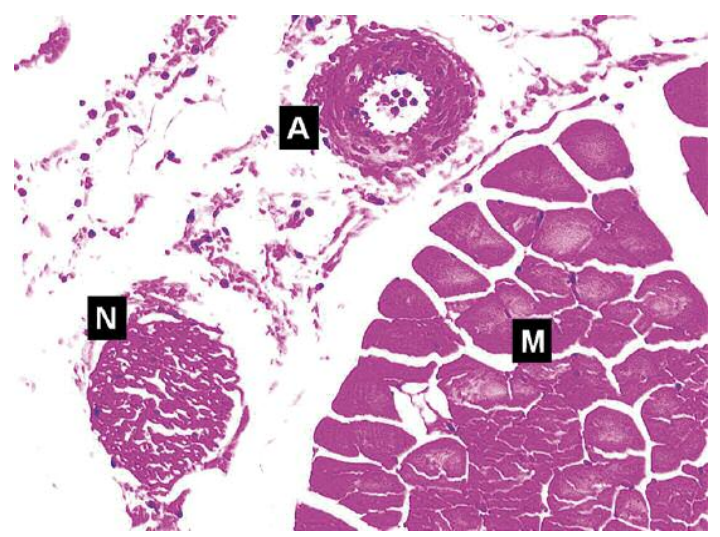

Figure 3. Normal diaphragm (M), supplying arteries (A) and nerves are seen (LM, $H+E, 40 x)$ 
Table I. Mean values of some parameters in the subarachnoid hemorrhage groups and the control group

\begin{tabular}{|lccc|}
\hline Parameter & Control group normal survivors & \multicolumn{2}{c|}{$\begin{array}{c}\text { Subarachnoid hemorrhage groups } \\
\text { with respiratory disturbance with respiratory arrest }\end{array}$} \\
\hline Normal neuron density & $13272 \pm 1202 / \mathrm{mm}^{3}$ & $11.412 \pm 670 / \mathrm{mm}^{3}$ & $7230 \pm 967 / \mathrm{mm}^{3}$ \\
\hline Degenerated neuron density & - & $2.240 \pm 450 / \mathrm{mm}^{3}$ & $5850 \pm 650 / \mathrm{mm}^{3}$ \\
\hline Respiration rhythm & $23 \pm 4 / \mathrm{min}$ & $31 \pm 6 / \mathrm{min}$ & $34 \pm 7 / \mathrm{min}$ \\
\hline
\end{tabular}

of cerebral blood flow. Parasympathetic fibers have vasodilatory effects and sympathetic fibers are vasospastic on cerebral arteries [15]. Cerebrovascular sensory nerves mainly originating from the first division of the ipsilateral trigeminal ganglion are known as the trigemino-cerebrovascular system [16]. Trigeminal sensory nerves project to the ipsilateral cerebral vasculature systems [17]. The cerebral vasculature, in particular the pial vessels, are densely supplied with noradrenergic sympathetic nerve fibers mainly originating in the superior cervical ganglion, accompanying the carotid artery, and projecting into the ipsilateral hemisphere [18-20]. Because upper cervical ganglions innervate the anterior spinal arteries (ASA) [21], ischemic injuries of these structures secondary to SAH may cause vasospasm of ASA. Because ASA

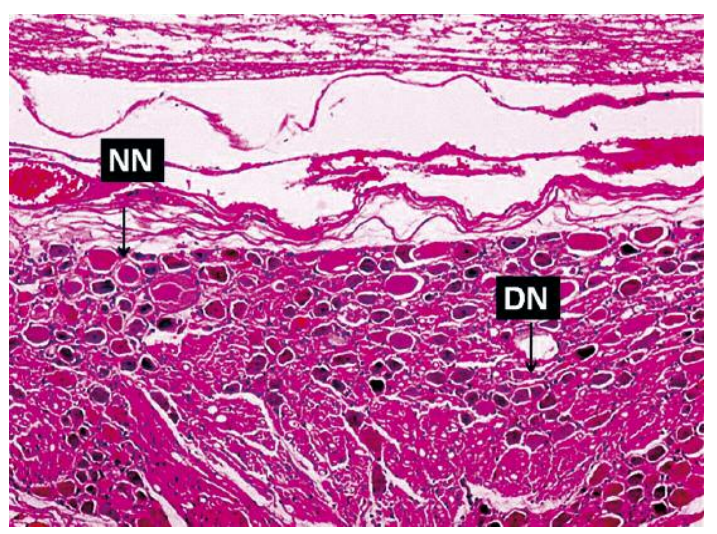

Figure 4. Degenerated $C_{4 D R G}$ is seen of a respiration arrest developed animal (NN - normal neuron, DN - degenerated neuron; LM, H + E, 40x)

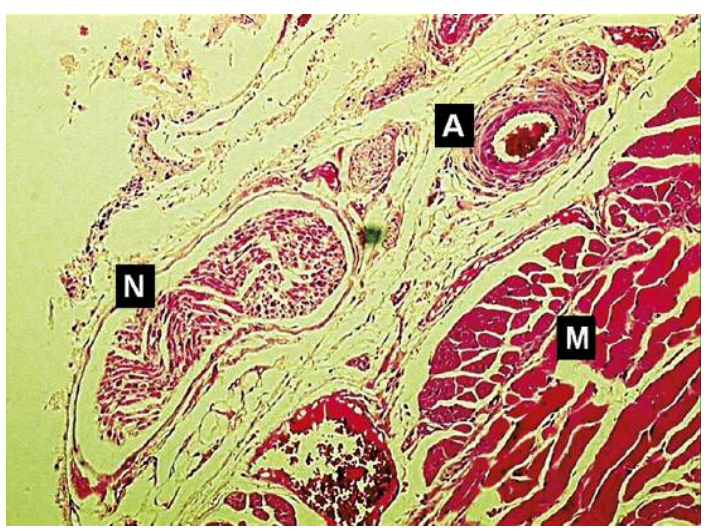

Figure 5. Paralyzed diaphragm (M), supplying arteries (A) and nerves are seen in a dead animal (LM, $H+E, 40 x)$ also supplies the phrenic nerve roots, ASA vasospasm triggers phrenic nerve ischemia and respiration disorder. Yasargil performed surgical ablation of the peri-adventitial sympathetic plexus from the arterial wall during craniotomy for intracranial aneurysmal clipping, thereby producing chronic denervation, and observed a low incidence of postoperative vasospasm [22, 23]. Intracerebral vessels constrict in response to cervical sympathetic stimulation and dilate when these fibers are interrupted. Efflux and reuptake of the neurotransmitter may be prevented by sympathectomy. Retrograde neuronal death is well established in dorsal root ganglia (DRG) after peripheral nerve injury or severe spinal cord trauma $[24,25]$. Neuronal death begins within the first day of peripheral axotomy and is limited up to 6 months [26]. Physical distance of the lesion to the cell body is the most important factor in neuronal death. Neurodegenerative changes have also been detected in DRG up to 12 weeks following transection of the sciatic nerve or lumbar spinal nerve roots in adult rats [27]. Not only motor neurons and DRG cells but also small neurons, presumably interneurons in the spinal cord, may undergo neuronal death as a result of neonatal peripheral nerve transection [28]. The neurodegeneration in DRG may result from the migration of mononuclear cells or apoptosis [29]. After serious craniocervical trauma, severely damaged DRG neurons were observed [25].

Although Shi et al. have shown that upper cervical ganglions innervate the ASA [21], ischemic

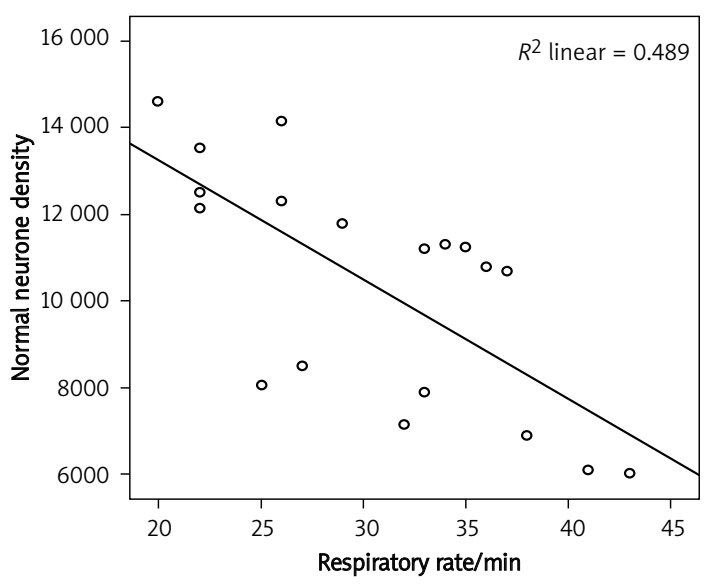

Figure 6. Scatter diagram showing correlations between normal neuron density and respiratory rate in all animals 
injuries of these structures secondary to SAH may cause vasospasm at the ASA. It is possible that SAH may cause vasospasm in the arteries supplying DRG and thus lead to ischemic degeneration in the DRG. The effects of vasospasm after SAH on DRG neurons are not well known. In the light of these studies, we propose that vasospasm after SAH can lead to damage of the third and the second sensorial neurons of the spino-cortical sensory pathways and result in neurodegeneration of DRG as seen after proximal axotomy, and vasospasm after $\mathrm{SAH}$ affecting upper sensory pathways may lead to neurodegeneration in $C_{4 D R G}$ [30]. That is why we investigated the numbers of normal neurons and degenerated neurons in $\mathrm{C}_{4 \mathrm{DRG}}$ in vasospasm after $\mathrm{SAH}$. An estimate of the number of live or degenerated neurons in $C_{4 D R G}$ was the basis of our results. Because previous counting methods have been open to bias, we used stereological methods to estimate the number of neurons. Stereology is a method to relate three-dimensional parameters of a structure from two-dimensional measurements obtained in the sections [31-36]. A detailed description of our dissector method was made [12-14, 29].

Diaphragmatic regions are recruited in a specialized manner either as part of a central motor unit during non-respiratory maneuvers, or vomiting and esophageal distension, mechanical loading, lung volume and postural changes [37]. The phrenic nerve divides into three to four branches when entering the diaphragm. These branches are classified as sternal, anterolateral, posterolateral, and crural [38]. D'Angelo et al. have shown that in response to respiratory stimuli the rabbit diaphragm behaves as a single unit under the command of the central respiratory control system [37]. Increasing $\mathrm{SAH}$ volumes were associated with greater abnormalities in the respiratory pattern, consisting of apnea and hyperventilation. These larger volumes were also associated with hypoxemia. Morbidity and mortality increased with increasing volumes of $\mathrm{SAH}$, and are believed to be the result of a combination of decreased cerebral and spinal cord blood flow, respiratory disturbances, and pulmonary diffusion defect [10]. Spinal cord hemisection at the C2 level interrupts these descending respiratory pathways to the ipsilateral phrenic motoneurons, subsequently leading to paralysis of the ipsilateral hemidiaphragm, dyspnea, and rapid shallow tachypnea. However, breathing function distorted due to the previously paralyzed hemidiaphragm can be restored by increasing respiratory drive. Kajana and Goshgarian suggest that compounds capable of regulating CAMP levels may be therapeutically useful in promoting functional recovery following spinal cord injury [39]. In another study, the authors found that respiratory failure is related to neurological outcome following $\mathrm{SAH}$, although it is not com- monly the primary cause of death from medical complications [11]. Lleva et al. studied electrocardiographic abnormalities after ischemic stroke and intracerebral hemorrhages and subarachnoid hemorrhage. However, they did not also mention phrenic nerve ischemic insults in their studies. We observed that phrenic nerve ischemia can result in important electrocardiographic abnormalities after $\mathrm{SAH}$ [40]. Because the phrenic nerve supplies somatosensory innervation of cardiorespiratory trees, phrenic nerve root injuries should be considered as an important factor in the development of cardiorespiratory disturbances after $\mathrm{SAH}$, meningitis, craniocerebral tumors and traumas. Although many authors have declared that the cause of cardiorespiratory disturbances is related to trigeminal nerve networks [41-43], we found that ischemic lesions of phrenic nerve roots after SAH may be considered an important etiological agent in such pathologies, which has not been mentioned in the literature. In the present study we examined the neuron density of $\mathrm{C}_{4 \mathrm{DRG}}$ from rabbits with experimental SAH using a cisternal blood injection model. This model is widely used to study the processes involved in the development and maintenance of cerebral vasospasm. We found low normal neuron density and high degenerated neuron density of $\mathrm{C}_{4 \mathrm{DRG}}$ in experimental SAH with respiratory disturbances and an inverse relationship between the degenerated neuronal density in the $C_{4 D R G}$ and respiratory rate. Paralyzed diaphragms were seen in animals with respiratory arrest due to $\mathrm{SAH}$. Kanat et al. showed that the neuron density of C3 dorsal root ganglia may be an important factor in the regulation of ASA volume values and the continuation of spinal cord blood flow in SAH [44]. We think that vasospasm after SAH affecting upper sensory pathways may lead to neurodegeneration in $C_{4 D R G}$ and can cause abnormalities in the respiratory pattern. Also it may be postulated that the neuron density of $C_{4 D R G}$ may be an important factor in the regulation of respiratory and non-respiratory maneuvers of the diaphragm, vomiting, esophageal distension, mechanical loading, lung volume, and postural changes. The low neuron density of $C_{4 D R G}$ due to vasospasm in SAH may cause dysfunction of the phrenic nerve and can be considered as an important factor affecting morbidity and mortality because of disturbed control of respiratory and nonrespiratory maneuvers of the diaphragm.

In conclusion, in this study, it was found that $\mathrm{SAH}$ resulted in neurodegeneration in DRG and neuron density of $C_{4 D R G}$ may be an important factor in the regulation and continuation of respiration. Low neuron density of $C_{4 D R G}$ may be considered as an important factor in the pathogenesis of severe respiratory disturbances in $\mathrm{SAH}$. 


\section{References}

1. Kassell NF, Drake CG. Timing of aneurysm surgery. Neurosurgery 1982; 10: 514-9.

2. Allen L, Foster RW, Morsan GP, Small RC. The relaxant effect of nicorandil in guinea pig isolated trachealis. $\mathrm{Br}$ J Pharmacol 1986; 187: 117-27.

3. Itoh T, Furukawa K, Kajiwara M, et al. Effects of 2-nicotinamidoethyl nitrate on smooth muscle cells and on adrenergic transmission in the guinea pig and porcine mesenteric arteries. J Pharmacol Exp Ther 1981; 218: 260-70.

4. Kassel NF, Sasaki T, Colohan A, Nazure G. Cerebral vasospasm following aneurysmal subarachnoid hemorrhage. Stroke 1985; 16: 562-72.

5. Waters A, Harder DR. Altered membrane properties of cerebral vascular muscle following subarachnoid hemorrhage in cat: an electrophysiological study. Changes in resting membrane potential and effect of the electrogenic pump potential contributing to E. Stroke 1985; 16: 990-7.

6. Buchanan KM, Elias LJ, Goplen GB. Differing perspectives on outcome after subarachnoid hemorrhage: the patient, the relative, the neurosurgeon. Neurosurgery 2000; 46: 831-8.

7. Carter BS, Buckley D, Ferraro R, Rordorf G, Ogilvy CS. Factors associated with reintegration to normal living after subarachnoid hemorrhage. Neurosurgery 2000; 46: 1326-33.

8. Medlock MD, Dulebohn SC, Elwood PW. Prophylactic hypervolemia without calcium channel blockers in early aneurysm surgery. Neurosurgery 1992; 30: 12-6.

9. Origitano TC, Wascher TM, Reichman OH, Anderson DE. Sustained increased cerebral blood flow with prophylactic hypertensive hypervolemic hemodilution ("triple- $\mathrm{H}$ " therapy) after subarachnoid hemorrhage. Neurosurgery 1990; 27: 729-39.

10. Rothberg C, Weir B, Overton T, Grace M. Responses to experimental subarachnoid hemorrhage in the spontaneously breathing primate. J Neurosurg 1980; 52: 302-8.

11. Gruber A, Reinprecht A, Görzer H, et al. Pulmonary function and radiographic abnormalities related to neurological outcome after aneurysmal subarachnoid hemorrhage. J Neurosurg 1998; 88: 28-37.

12. Gardi JE, Nyengaard JR, Gundersen HJ. Automatic sampling for unbiased and efficient stereological estimation using the proportionator in biological studies. J Microsc 2008; 230: 108-20.

13. Gundersen HJ. Stereology of arbitrary particles. A review of unbiased number and size estimators and the presentation of some new ones, in memory of William $R$ Thompson. J Microsc 1986; 143: 3-45.

14. Gundersen HJ, Bendtsen TF, Korbo L, et al. Some new, simple and efficient stereological methods and their use in pathological research and diagnosis. APMIS 1988; 96 : 379-94.

15. Hara H, Zhang QJ, Kuroyanagi T, Kobayashi S. Parasympathetic cerebrovascular innervation: an anterograde tracing from the sphenopalatine ganglion in the rat. Neurosurgery 1993; 32: 822-7.

16. Liu-Chen LY, Mayberg MR, Moskowitz MA. Immunohistochemical evidence for a substance P-containing trigeminovascular pathway to pial arteries in cats. Brain Res 1983; 268: 162-6.

17. Arbab MAR, Wiklund L, Svendgaard NA. Origin and distribution of cerebral vascular innervation from superior cervical, trigeminal and spinal ganglia investigated with retrograde and anterograde WGA-HRP tracing in the rat. Neuroscience 1986; 19: 695-708.
18. Edvinsson L. Neurogenic mechanisms in the cerebrovascular bed: autonomic nerves, amine receptors and their effects on cerebral blood flow. Acta Physiol Scand Suppl 1975; 427: 1-35.

19. Kassel NF, Sasaki T, Colohan A, Nazure G. Cerebral vasospasm following aneurysmal subarachnoid hemorrhage. Stroke 1985; 16: 562-72.

20. Tuor UI. Local distribution of the effects of sympathetic stimulation on cerebral blood flow in the rat. Brain Res 1990; 529: 224-31.

21. Shi TJ, Tandrup T, Bergman E, Xu ZQ, Ulfhake B, Hokfelt T. Effect of peripheral nerve injury on dorsal root ganglion neurons in the $\mathrm{C} 57 \mathrm{BL} / 6 \mathrm{~J}$ mouse: marked changes both in cell numbers and neuropeptide expression. Neuroscience 2001; 105: 249-63.

22. Yașargil MG. A legacy of microneurosurgery: memoirs, lessons, and axioms. Neurosurgery 1999; 45: 1025-92.

23. Yasargil MG. The advent of microsurgery. Mt Sinai J Med 1997; 64: 164-5.

24. Ma J, Novikov LN, Wiberg M, Kellerth JO. Delayed loss of spinal motoneurons after peripheral nerve injury in adult rats: a quantitative morphological study. Exp Brain Res 2001; 139: 216-23.

25. Taiushev KG. Segment-by-segment histological analysis of the cervical part of the spinal cord, roots of the cerebrospinal nerves and ganglia in severe cranio-cerebral trauma. Arkh Anat Gistol Embriol 1989; 96: 16-23.

26. McKay HA, Brannstrom T, Wiberg M, Terenghi G. Primary sensory neurons and satellite cells after peripheral axotomy in the adult rat: timecourse of cell death and elimination. Exp Brain Res 2002; 142: 308-18.

27. Hu P, McLachlan EM. Macrophage and lymphocyte invasion of dorsal root ganglia after peripheral nerve lesions in the rat. Neuroscience 2002; 112: 23-38.

28. Oliveira AL, Risling M, Negro A, Langone F, Cullheim S. Apoptosis of spinal interneurons induced by sciatic nerve axotomy in the neonatal rat is counteracted by nerve growth factor and ciliary neurotrophic factor. J Comp Neurol 2002; 447: 381-93.

29. Groves MJ, Christopherson T, Giometto B, Scaravilli F. Axotomyinduced apoptosis in adult rat primary sensory neurons. J Neurocytol 1997; 26: 615-24.

30. Aydin MD, Erdogan AR, Cevli SC, Gundogdu C, Dane S, Diyarbakirli S. Ganglionary mechanisms of spasticity and ileus in cerebral hemorrhage: an experimental study. Int J Dev Neuroscience 2006; 24: 455-9.

31. Aydin MD, Dane S, Gundogdu C, Gursan N. Neurodegenerative effects of monopolar electrocauterization on spinal ganglia in lumbar disc surgery. Acta Neurochir (Wien) 2004; 146: 1125-9.

32. Aydin MD, Yildirim OS, Gundogdu C, Onder A, Okur A. Thrombogenetic effect of facet denervation using in disc surgery on spinal radicular arteries: an experimental study. Minim Invasive Neurosurg 2006; 49: 328-30.

33. Bendsen E, Byskov AG, Laursen SB, Larsen HPE, Andersen CY, Westergaard LG. Number of germ cells and somatic cells in human fetal testes during the first weeks after sex differentiation. Hum Reprod 2003; 18: 13-8.

34. Chang Z, Shen Z, Sun Y, Wang N, Cao D. Early repair treatment of electrical burns and recovery of tendons and nerves. Report of 194 operations. Ann NY Acad Sci 1999; 888: 327-33

35. Gundersen HJG. Notes on the estimation of the numerical density of arbitrary particles: the edge effect. J Microsc 1977; 111: 219-23.

36. Sterio DC. The unbiased estimation of number and sizes of arbitrary particles using the disector. J Microsc 1984; 134: $127-36$ 
37. D'Angelo E, Monaco A, D'Angelo E, Pecchiari M. Motor control of the diaphragm in anesthetized rabbits. Respir Physiol Neurobiol 2010; 170: 141-9.

38. Turgut HB, Peker T, Karaköse M, Anil A, Gülekon N, Demirta K. Phrenic nerve distribution in the rabbit diaphragm and morphometric analysis of nerve branches. Anat Histol Embryol 2006; 35: 357-60.

39. Kajana S, Goshgarian HG. Administration of phosphodiesterase inhibitors and an adenosin A1 receptor antagonist induces phrenic nerve recovery in high cervical spinal cord injured rats. Expl Neurol 2008; 210: 671-80.

40. Paul L, Wilbert AS, Harshad A. Prevalence of electrocardiographic abnormalities in patients with ischemic stroke, intracerebral hemorrhage, and subarachnoid hemorrhage. Arch Med Sci 2008; 4: 259-62.

41. Spiriev T, Kondoff S, Schaller B. Cardiovascular changes after subarachnoid hemorrhage initiated by the trigeminocardiac reflex-first description of a case series. J Neurosurg Anesthesiol 2011; 23: 379-80.

42. Spiriev T, Kondoff S, Schaller B. Trigeminocardiac reflex during temporary clipping in aneurismal surgery: first description. J Neurosurg Anesthesiol 2011; 23: 271-2.

43. Schaller B, Probst R, Strebel S, Gratzl O. Trigeminocardiac reflex during surgery in the cerebellopontine angle. J Neurosurg 1999; 90: 215-20.

44. Kanat A, Yilmaz A, Aydin MD, Musluman M, Altas S, Gursan N. Role of degenerated neuron density of dorsal root ganglion on anterior spinal artery vasospasm in subarachnoid hemorrhage: experimental study. Acta Neurochir (Wien) 2010; 152: 2167-72. 